\title{
Vasoconstrictor Role for Vasopressin in Experimental Heart Failure in the Rabbit
}

Leonard Arnolda, Barry P. McGrath, Michael Cocks, and Colin I. Johnston

Monash University Department of Medicine, Prince Henry's Hospital, Melbourne, 3004, Victoria, Australia

\begin{abstract}
Vasopressin's role as a vasoconstrictor in chronic heart failure was examined in rabbits with adriamycin cardiomyopathic congestive heart failure. Chronic adriamycin treatment resulted in a decrease in cardiac output $(829 \pm 38-610 \pm 36 \mathrm{ml} / \mathrm{min}, P$ $<0.005)$ and blood pressure $(83 \pm 2-76 \pm 3 \mathrm{mmHg}, P<0.01)$, and an increase in peripheral resistance $(8,377 \pm 381-10,170 \pm 657$ dyn-s-cm $\left.^{-5}, P<0.05\right)$. Plasma renin activity $(4.7 \pm 0.6-10.9 \pm 2.8$ ng angiotensin $\mathrm{I} / \mathrm{ml} \cdot \mathrm{h})$ and norepinephrine $(0.7 \pm 0.1-1.3 \pm 0.2$ pmol/ml, $P<0.05$ ) increased while plasma vasopressin levels did not change. Vasopressin infusion, however, produced significantly greater increases in peripheral resistance in animals with heart failure than in controls. Moreover, a specific vasopressin vascular antagonist reduced blood pressure $(7 \pm 3 \%)$ and peripheral resistance (14 $\pm 4 \%)$ and increased cardiac output (10 $\pm 3 \%)$ in animals with heart failure but had no cardiovascular effects in normal rabbits. These results suggest that vascular sensitivity to vasopressin is increased in heart failure, and that it contributes significantly to the increased afterload in heart failure despite normal plasma levels. In this model of severe, chronic heart failure the sympathetic, renin-angiotensin, and vasopressin systems all appear to be activated.
\end{abstract}

\section{Introduction}

The failing heart is exquisitely sensitive to changes in the resistance against which it ejects. Thus, in low output congestive heart failure, compensatory vasoconstriction mediated by neurohumoral factors may be detrimental. Activation of the sympathetic nervous system $(1,2)$ and the renin-angiotensin system $(2,3)$ have been implicated as vasoconstrictor mechanisms. A third important vasoconstrictor hormone system that may be involved is vasopressin. Plasma levels of vasopressin have been elevated in some patients with heart failure $(4,5)$ and in some experimental models of heart failure $(6,7)$. These studies have, in general, been concerned with the antidiuretic rather than the vasopressor action of vasopressin. The recent development of specific antagonists to the vascular receptors for vasopressin (8) has led to a defined role for vasopressin in cardiovascular adaptation to the stresses of hemorrhage (9), dehydration (10), adrenal insufficiency (11), and in experimental hypertension (12). In this study we examined the vascular actions of vasopressin in adriamycin cardiomyopathic congestive heart failure in the

Address correspondence and reprint requests to Dr. C. I. Johnston, U. of Melbourne Department of Medicine, Austin Hospital, Heidelberg, Melbourne, 3004, Victoria, Australia. 1986.

Received for publication 23 October 1985 and in revised form 13 May

J. Clin. Invest.

(c) The American Society for Clinical Investigation, Inc.

0021-9738/86/09/0674/06 \$1.00

Volume 78, September 1986, 674-679 rabbit. This is an animal model of chronic, low output heart failure that closely resembles human heart failure $(13,14)$. We used three separate experimental approaches to evaluate the role of vasopressin in this model. These approaches involved measuring resting plasma vasopressin levels, determining the hemodynamic effects of vasopressin infusion, and examining the results of blockade of vasopressin vascular receptors with specific antipressor vasopressin vascular antagonists (AVPA). ${ }^{1}$ Our results show that vasopressin contributes to the altered hemodynamic pattern of reduced cardiac output and increased peripheral vascular resistance in this model of chronic heart failure.

\section{Methods}

Rabbits of either sex, $2.5-3.5 \mathrm{~kg}$ in weight, of a mixed strain derived from New Zealand White and English breeds, were obtained from Monash University Central Animal House. The experiments detailed below were approved by the Monash University Research Advisory and Ethics Committee and conformed to the guidelines set out by the National Health and Medical Research Council of Australia. The model of adriamycin cardiomyopathic congestive heart failure has been described in detail before (14). In brief, adriamycin (Farmitalia Carlo Erba, Milan, Italy) was administered via a marginal ear vein in a dose of $1 \mathrm{mg} / \mathrm{kg}$ twice weekly for $8 \mathrm{wk}$. This is a modification of the technique described by Jaencke et al. (13) which produces maximum cardiac damage with minimal marrow toxicity.

Studies were carried out in conscious unrestrained rabbits. All animals had a chronically implanted aortic thermistor catheter for measurement of cardiac output by the thermodilution technique using $5 \%$ dextrose at room temperature injected into the right atrium. The thermistor catheter was inserted into the aorta via the left ilio-lumbar artery under anesthesia and positioned just below the renal arteries. This technique was previously described by Korner et al. (15). The animals were allowed to recover for at least 2 wk after catheterization before any measurements were performed. Adriamycin-treated animals were studied 2 wk after the last dose of adriamycin. Right atrial and central ear artery catheters were inserted under local anaesthesia ( $2 \%$ xylocaine) at least $1 \mathrm{~h}$ before a study.

Hemodynamic studies. Paired hemodynamic studies were performed in 10 animals. These animals were studied initially before treatment with adriamycin and again after $8 \mathrm{wk}$ of adriamycin treatment. A further 37 normal animals and 7 adriamycin cardiomyopathic animals were also studied. Each hemodynamic study consisted of five sets of the following measurements: mean blood pressure, right atrial pressure, cardiac output, and heart rate. For each animal the results reported are the averages of the five sets of measurements.

Measurement of vasoactive hormones. Paired blood samples for measurement of plasma vasoactive hormones were drawn in 15 animals before treatment with adriamycin and again 2 wk after cessation of 8 wk of adriamycin treatment. Plasma hormonal levels were also measured in another 39 normal animals and in a further 5 adriamycin cardiomyopathic animals. On each occasion, $8 \mathrm{ml}$ of blood was drawn from the right atrial catheter for measurement of arginine vasopressin (AVP) and osmolality, plasma renin activity (PRA), and norepinephrine (NE), the volume being replaced with $0.9 \%$ saline. The sampling procedure did

1. Abbreviations used in this paper: AI, angiotensin I; AVP, arginine vasopressin; AVPA, vasopressin vascular antagonist; NE, norepinephrine; PRA, plasma renin activity. 
not alter plasma levels of AVP, PRA, or NE in a preliminary study. Blood samples were collected on ice, immediately centrifuged, and plasma samples stored at $-20^{\circ} \mathrm{C}$ until assayed by radioimmunoassay for PRA (15) and AVP (16) and radioenzymatic assay for NE (17).

Vasopressin infusion studies. The hemodynamic response to infused vasopressin was examined in five normal controls and five animals with adriamycin-induced heart failure. Vasopressin (8-arginine vasopressin, Peninsular Laboratories, Belmont, CA) was infused at $2.5 \mathrm{ng} / \mathrm{kg} \cdot \mathrm{min}$ and $25 \mathrm{ng} / \mathrm{kg} \cdot \mathrm{min}$ for $30 \mathrm{~min}$ each via a catheter (polyethylene tetrafluoroethylene, $0.47 \mathrm{~mm}$ i.d., Terumo [Australia] Pty. Ltd., Melbourne, Australia) in a marginal ear vein. Both doses are subpressor in normal rabbits (18). Resting hemodynamic measurements were made as previously described and repeated at the end of each infusion. $5 \mathrm{ml}$ of blood was drawn at baseline and at the end of each infusion period to measure vasopressin levels. The volume withdrawn was replaced with $0.9 \%$ saline. In each case the $2.5-\mathrm{ng} / \mathrm{kg} \cdot \min$ infusion was followed by the $25-\mathrm{ng} /$ $\mathrm{kg} \cdot \mathrm{min}$ infusion. One rabbit with heart failure died shortly after commencing the higher dose infusion and the results for this infusion rate in animals with heart failure were from four rabbits only.

AVPA studies. The hemodynamic responses to an AVPA were examined in 10 rabbits with heart failure (group 1) and in 5 normal controls (group 3). The effect of vehicle alone was also examined in six rabbits with heart failure (group 2). In these studies, five sets of resting hemodynamic measurements were made (as previously described) immediately before the bolus administration of AVPA or vehicle and this was repeated 15 min later.

Two AVPA were used: [1-( $\beta$-mercapto- $\beta, \beta$-cyclopentamethylenepropionic acid),8-D-arginine]vasopressin or $\mathrm{d}\left(\mathrm{CH}_{2}\right)_{5} \mathrm{DAVP}$ (From Dr. M. Manning, Dept. of Biochemistry, Medical College of Ohio, Toledo, $\mathrm{OH})$, and [ $1-(\beta$-mercapto- $\beta, \beta$-cyclopentamethylenepropionic acid),2-(dmethyl)-tyrosine]AVP or $\mathrm{d}\left(\mathrm{CH}_{2}\right)_{5}$ Tyr (methyl) AVP (Peninsula Laboratories). These have very similar antivasopressor potencies $\left(\mathrm{pA}_{2}\right.$ : $8.52 \pm 0.03$ and $8.67 \pm 0.02$, respectively) and are very weak antidiuretic agonists (both $0.31 \mathrm{U} / \mathrm{mg})(8,19)$. We used $30 \mu \mathrm{g} / \mathrm{kg}$ of either antagonist, a dose which was shown in a preliminary study to abolish the pressor response to bolus doses of $100 \mathrm{ng} / \mathrm{kg} \cdot$ AVP for $>1 \mathrm{~h}$.

Statistics. Results are expressed as the mean \pm standard error of the mean. Within group, analysis was performed by paired $t$ test while differences between groups were analyzed by unpaired $t$ test. All $P$ values were two-tailed and $P<0.05$ was considered to be statistically significant.

\section{Results}

After 8 wk of adriamycin therapy all animals had signs of severe congestive heart failure at postmortem examination, as evidenced by severe cardiac dilation and the accumulation of fluid in pleural, pericardial, and peritoneal cavities.

Resting hemodynamic measurements. The results of paired hemodynamic measurements in resting animals studied before and after adriamycin treatment are shown in Fig. 1. In this group of 10 animals, mean blood pressure fell from $83 \pm 2$ to $76 \pm 3$ $\mathrm{mmHg}(P<0.01)$. Cardiac output decreased from $829 \pm 38 \mathrm{ml} /$ $\min$ to $610 \pm 36 \mathrm{ml} / \mathrm{min}(P<0.005)$, while peripheral resistance increased from $8,377 \pm 381$ dyn-s-cm ${ }^{-5}$ to $10,170 \pm 657$ dyn-s$\mathrm{cm}^{-5}(P<0.05)$.

The pretreatment hemodynamic values in these 10 animals studied sequentially were similar to our results in the larger group of 37 normal animals, while posttreatment values were similar to those in seven other adriamycin-treated animals. This data was combined and the results are shown in Table I. Adriamycintreated animals had a significantly reduced cardiac output $(38 \%$ decrease, $P<0.001)$ and an increased peripheral resistance $(32 \%$ increase, $P<0.005$ ) compared with normal controls. Heart rate was also increased in heart failure $(13 \%$ increase, $P<0.05)$. However, blood pressure and right atrial pressure were not significantly different from control animals statistically.

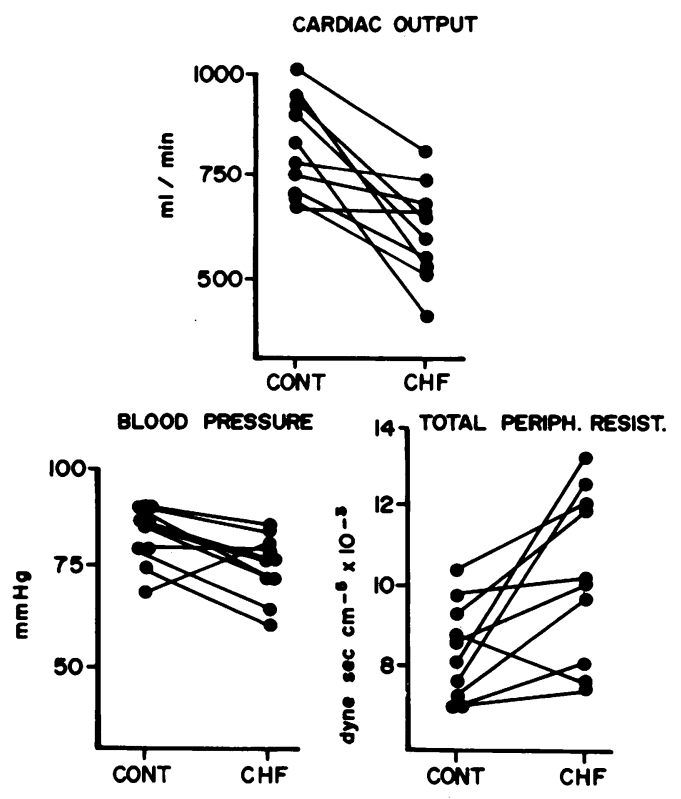

Figure 1. Changes in cardiac output, blood pressure, and peripheral resistance in rabbits with adriamycin cardiomyopathic heart failure. Cont, control (i.e., resting hemodynamic measurements in rabbits before treatment with adriamycin); CHF, resting measurements in the same animals $10 \mathrm{wk}$ after adriamycin treatment was initiated and 2 wk after the last dose of adriamycin.

$P R A, N E$, and AVP results. Paired plasma hormonal measurements in 15 animals studied before and after adriamycin treatment demonstrated an increase in renin levels from $4.7 \pm 0.6$ $\mathrm{ng}$ angiotensin $\mathrm{I}(\mathrm{AI}) / \mathrm{ml} \cdot \mathrm{h}$ to $10.9 \pm 2.8 \mathrm{ng} \mathrm{AI} / \mathrm{ml} \cdot \mathrm{h}(n=15, P$ $<0.05)$, and in NE from $0.7 \pm 0.1$ to $1.3 \pm 0.2 \mathrm{pmol} / \mathrm{ml}(n=15$, $P<0.05)$, while vasopressin levels did not change $(6.3 \pm 1.4-$ $8.4 \pm 2.0 \mathrm{fmol} / \mathrm{ml} ; n=14, P>0.1)$.

The pretreatment hormonal levels in these paired studies were similar to those measured in the larger group of 39 normal controls, and posttreatment values were similar to the five additional adriamycin-treated animals. The combined results are shown in Fig. 2. PRA was elevated in the heart failure group to about two-and-one-half times the level in controls $(10.0 \pm 2.2$ vs. $4.3 \pm 0.5 \mathrm{ng} / \mathrm{ml}, P<0.001)$. Resting NE levels in the heart failure group were double the control values $(1.3 \pm 0.2$ vs. $0.6 \pm 0.1 \mathrm{pmol} /$ $\mathrm{ml}, P<0.005)$. Plasma AVP was not significantly different in heart failure $(7.4 \pm 1.5 \mathrm{fmol} / \mathrm{ml})$ and control animals $(10.8 \pm 1.5$ $\mathrm{fmol} / \mathrm{ml}$ ), and plasma osmolality was also similar in the two groups ( $285 \pm 3$ vs. $283 \pm 1$ mosM, $P>0.1)$.

In the heart failure group, plasma renin was correlated positively with peripheral resistance $(r=0.61, n=15, P<0.01)$, and negatively with cardiac output $(r=-0.70, n=15, P<0.01)$. Plasma levels of NE and vasopressin did not correlate with any of the hemodynamic variables.

Response to vasopressin infusion. In control animals $(n=5)$, vasopressin infused at $2.5 \mathrm{ng} / \mathrm{kg} \cdot \min$ for 30 min produced a plasma vasopressin level of $131 \pm 26 \mathrm{fmol} / \mathrm{ml}$, but did not change mean blood pressure, cardiac output, or peripheral resistance (Table II). During vasopressin infusion at $25 \mathrm{ng} / \mathrm{kg} \cdot \mathrm{min}$, giving a plasma vasopressin level of $2,205 \pm 531 \mathrm{fmol} / \mathrm{ml}$, mean blood pressure did not change significantly, but cardiac output was decreased, peripheral resistance increased, and heart rate decreased compared with the control levels (Table II).

In animals with heart failure, the lower dose vasopressin 
Table I. Resting Hemodynamic Measurements in Normal Rabbits and Rabbits in Heart Failure

\begin{tabular}{|c|c|c|}
\hline & Normal controls & Heart failure \\
\hline$n$ & 47 & 17 \\
\hline Cardiac output $(\mathrm{ml} / \mathrm{min})$ & $796 \pm 16$ & $570 \pm 26^{*}$ \\
\hline Blood pressure $(\mathrm{mmHg})$ & $81 \pm 1$ & $77 \pm 3$ \\
\hline Right atrial pressure $(\mathrm{mmHg})$ & $-0.4 \pm 0.3$ & $0.2 \pm 0.7$ \\
\hline $\begin{array}{l}\text { Total peripheral resistance } \\
(\text { dyn-s-cm }\end{array}$ & $8,346 \pm 247$ & $11,035 \pm 741 \ddagger$ \\
\hline Heart rate (beats/min) & $253 \pm 7$ & $287 \pm 15 \S$ \\
\hline
\end{tabular}

$* P<0.001$.

$\ddagger P<0.005$.

$\S P<0.05$.

infusion, producing similar vasopressin levels of $75 \pm 20 \mathrm{fmol} /$ $\mathrm{ml}$, again did not change blood pressure $(+2 \mathrm{mmHg})$, but did produce a significant decrease in cardiac output $(110 \pm 27 \mathrm{ml} /$ $\mathrm{min})$ and an increase in peripheral resistance $(2,763 \pm 371$ dyn$\left.\mathrm{s}-\mathrm{cm}^{-5}\right)$. The higher dose vasopressin infusion achieved plasma levels of $667 \pm 162 \mathrm{fmol} / \mathrm{ml}$ without a change in blood pressure, but cardiac output was further reduced $(221 \pm 63 \mathrm{ml} / \mathrm{min})$ and peripheral vascular resistance further increased $(5,838 \pm 790$ dyns-cm ${ }^{-5}$ ) (Fig. 3).

The effects of vasopressin infusion on peripheral vascular resistance in the two groups are shown in Fig. 3. At both infusion rates, despite lower plasma vasopressin levels, the changes in total peripheral resistance were significantly higher in the rabbits with heart failure than in normal rabbits; at the low infusion rate of $2.5 \mathrm{ng} / \mathrm{kg} \cdot \mathrm{min}$ the changes were $(2,763 \pm 371$ vs. $27 \pm 477$ dyn-s-cm $\left.{ }^{-5}, P<0.01\right)$ at the higher dose infusion $(5,838 \pm 790$ vs. $2,538 \pm 694$ dyn-s-cm ${ }^{-5}, P<0.01$ ). The change in resistance in the heart failure animals with the lower dose infusion was equivalent to that seen at the tenfold higher dose in the controls.

Hemodynamic response to $A V P A$. The hemodynamic response to the antagonist of the pressor effects of vasopressin are summarized in Fig. 4. Administration of $30 \mathrm{ng} \cdot \mathrm{kg}$ of the AVPA to 10 animals with heart failure resulted in a significant increase

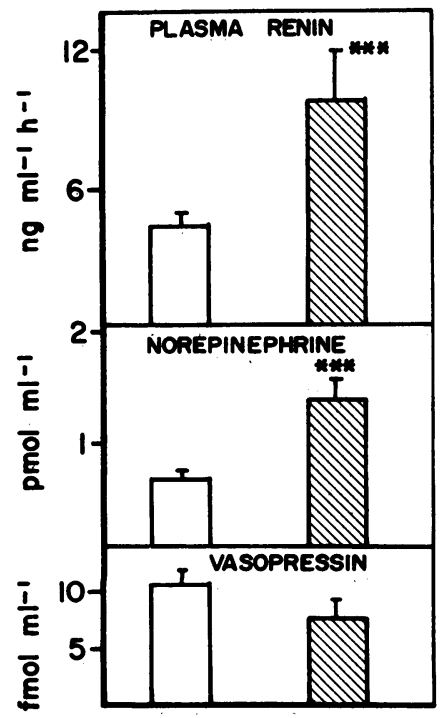

Figure 2. PRA, NE, and AVP in normal controls $(n=54)$ and rabbits with heart failure $(n=20)$. Normal controls, $\square$; heart failure, $\square$. *** Indicates $P$ $<0.005$.
Table II. Results of Vasopressin Infusion in Normal Rabbits and Rabbits with Heart Failure

\begin{tabular}{|c|c|c|c|}
\hline & Control & $2.5 \mathrm{ng} / \mathrm{kg} / \mathrm{min}$ & $25 \mathrm{ng} / \mathrm{kg} / \mathrm{min}$ \\
\hline \multicolumn{4}{|c|}{ A Normal rabbits } \\
\hline \multicolumn{4}{|c|}{ Plasma vasopressin } \\
\hline$\left(\mathrm{fmol} \mathrm{ml^{-1 }}\right)$ & $9.4 \pm 4.8$ & $131 \pm 26$ & $2,205 \pm 531$ \\
\hline \multicolumn{4}{|l|}{ Blood pressure } \\
\hline$(\mathrm{mmHg})$ & $84 \pm 6$ & $80 \pm 5$ & $82 \pm 4$ \\
\hline \multicolumn{4}{|l|}{ Cardiac output } \\
\hline$\left(m l \min ^{-1}\right)$ & $743 \pm 29$ & $712 \pm 18$ & $583 \pm 38^{*}$ \\
\hline \multicolumn{4}{|l|}{ Peripheral } \\
\hline$\left(d y n-s-\mathrm{cm}^{-5}\right)$ & $8,945 \pm 555$ & $8,971 \pm 618$ & $11,483 \pm 854^{*}$ \\
\hline \multicolumn{4}{|l|}{ Heart rate } \\
\hline (beats min $^{-1}$ ) & $229 \pm 12$ & $205 \pm 11$ & $185 \pm 16^{*}$ \\
\hline \multicolumn{4}{|c|}{$\begin{array}{l}\text { B Rabbits with heart } \\
\text { failure }\end{array}$} \\
\hline \multicolumn{4}{|c|}{ Plasma vasopressin } \\
\hline$\left(\mathrm{fmol} \mathrm{ml^{-1 }}\right)$ & $5.6 \pm 2.1$ & $75 \pm 20$ & $667 \pm 162$ \\
\hline \multicolumn{4}{|l|}{ Blood pressure } \\
\hline$(m m H g)$ & $85 \pm 3.6$ & $86 \pm 5.8$ & $89 \pm 6$ \\
\hline \multicolumn{4}{|l|}{ Cardiac output } \\
\hline$\left(m l \min ^{-1}\right)$ & $656 \pm 46$ & $546 \pm 29 \ddagger$ & $466 \pm 20 \ddagger$ \\
\hline \multicolumn{4}{|l|}{ Peripheral } \\
\hline$\left(d y n-s-\mathrm{cm}^{-5}\right)$ & $10,528 \pm 924$ & $13,023 \pm 1,215 \ddagger$ & $15,526 \pm 804 \ddagger$ \\
\hline \multicolumn{4}{|l|}{ Heart rate } \\
\hline (beats/min) & $266 \pm 28$ & $243 \pm 32$ & $201 \pm 22^{*}$ \\
\hline
\end{tabular}

$* P<0.05$ compared with preinfusion levels. $\ddagger P<0.01$ compared with preinfusion levels.

in cardiac output $(518 \pm 46-562 \pm 43 \mathrm{ml} \cdot \mathrm{min}, P<0.005)$ associated with a significant fall in blood pressure (76 $\pm 4-71 \pm 5$ $\mathrm{mmHg}, P<0.05)$ due to a marked decrease in calculated total

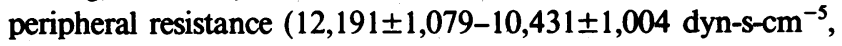
$P<0.01$ ).

The administration of vehicle to animals in heart failure did not alter any of these hemodynamic variables (Gp $2, n=6)$, nor did the administration of AVPA to normal rabbits (Gp 3, $n=5$ ) produce any hemodynamic changes.

Changes in PRA and NE in response to $A V P A$. The changes in PRA and NE in response to vasopressin blockade in heart failure are shown in Table III. PRA decreased significantly $(P$ $<0.05)$ and NE increased $(P<0.05)$ after administration of AVPA to these animals. Neither PRA nor NE were significantly altered after AVPA in normal animals (Table III) or after vehicle in heart failure (PRA: $17 \pm 5.5-15 \pm 5.7 \mathrm{ng} \mathrm{AI} / \mathrm{ml}$ per $\mathrm{h}$; NE: $1.0 \pm 0.2-1.1 \pm 0.1 \mathrm{pmol} / \mathrm{ml})$.

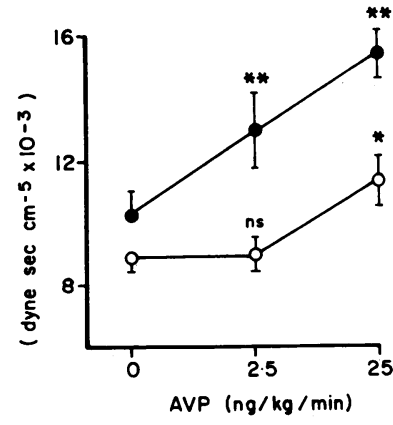

Figure 3. Changes in peripheral resistance with AVP infusion in normal controls $(n=5,0)$ and rabbits in heart failure $(n=5, \bullet) .{ }^{*} P$ $<0.05$ and $* * P<0.01$ when compared with preinfusion level in each group. ns, Not significant. 


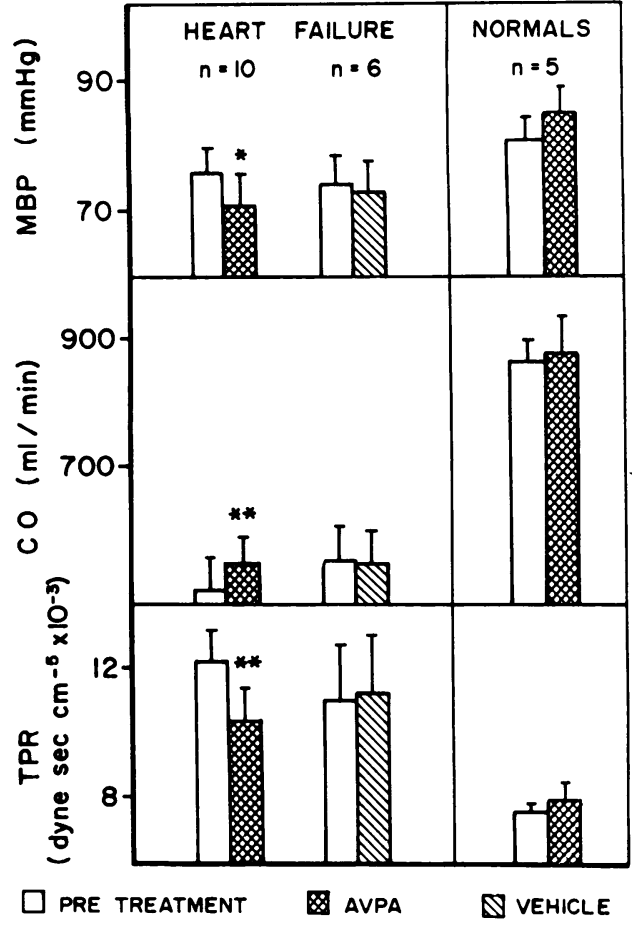

Figure 4. Changes in mean blood pressure (MBP), cardiac output (CO), and total peripheral resistance (TPR) in response to $30 \mu \mathrm{gg}^{-1}$ of AVPA or vehicle in rabbits with heart failure. The right panel shows the response to AVPA in normal controls. ${ }^{*} P<0.05$ and ${ }^{* *} P$ $<0.01$ when compared with corresponding pretreatment levels.

\section{Discussion}

The results of this study show that chronic administration of adriamycin in rabbits produced a cardiomyopathy with the characteristic hemodynamic and hormonal changes of low output heart failure. These results confirm and extend the results of our previous study in this model of heart failure (14). The fall in cardiac output observed in the adriamycin-treated animals occurred despite a resting tachycardia and was associated with a significant increase $(32 \%)$ in vascular resistance. Right atrial pressure did not increase, which is perhaps surprising in view of the cardiac dilation and hepatic congestion observed in the model $(13,14)$. However, it should be pointed out that only resting hemodynamic measurements were made in this study and the animals were not subject to any stress to examine myocardial reserve. There is also some evidence that adriamycin may affect the left ventricle more than the right (13).

Table III. Changes in PRA and NE after AVPA in Normal Controls $(n=5)$ and in Rabbits with Heart Failure $(n=10)$

\begin{tabular}{|c|c|c|c|c|}
\hline & \multicolumn{2}{|l|}{ Controls } & \multicolumn{2}{|l|}{ Heart failure } \\
\hline & Pretreatment & AVPA & Pretreatment & AVPA \\
\hline $\begin{array}{l}\text { PRA (ng } A I / m l \\
\text { per } h)\end{array}$ & $1.03 \pm 0.3$ & $1.0 \pm 0.3$ & $13.0 \pm 3.7$ & $10.4 \pm 3.3^{*}$ \\
\hline $\begin{array}{l}\text { Plasma NE } \\
\quad(p m o l / m l)\end{array}$ & $1.1 \pm 0.4$ & $1.0 \pm 0.4$ & $1.2 \pm 0.2$ & $1.5 \pm 0.2^{*}$ \\
\hline
\end{tabular}

* $n=P<0.05$ when compared with pretreatment level.
An increase in total peripheral resistance is a characteristic feature of low output heart failure and is considered to be due to the activation of vasoconstrictor systems. In this study the increased peripheral vascular resistance in adriamycin cardiomyopathic heart failure could be explained, in part, by significant activation of both the sympathetic nervous system and the reninangiotensin system.

Increased sympathetic activity was suggested by the increase in plasma NE levels and resting heart rate. The marked increase in PRA levels in treated animals and the significant correlation between PRA and peripheral vascular resistance in the heart failure group provide evidence for a significant contribution of the renin-angiotensin system. Moreover, the renin-angiotensin system appears to be activated as early as $4 \mathrm{wk}$ in this model of heart failure (14). These findings are in keeping with the extensive literature that supports a role for the sympathetic nervous system and renin-angiotensin system in heart failure based not only on the measurement of resting hormone levels but also on the effect of blockade of these systems (1-3).

Vasopressin is a third vasoconstrictor whose importance in cardiovascular homeostasis in dehydration (10), hemorrhage (9) adrenal insufficiency (11), and experimental hypertension (12) has been confirmed with the advent of specific antagonists to the vascular actions of vasopressin $(8,19)$. Vasopressin levels may be elevated in heart failure, particularly when considered in relation to osmolality, which is often reduced $(4,5)$. Most studies however have examined the contribution of vasopressin to fluid and electrolyte abnormalities rather than to the vasoconstriction that occurs in heart failure (4-7).

Two recent studies have focussed on the vascular actions of AVP in heart failure. Riegger et al. (20) reported that the AVP antagonist $\mathrm{d}\left(\mathrm{CH}_{2}\right)_{5}$ Tyr(Me) AVP had no significant hemodynamic effect in rats with heart failure produced by a large aortocaval shunt. However, this is a model of high output heart failure and it is difficult to measure any changes in peripheral vascular resistance in the native circulation in this model because of the dominant influence of the low resistance shunt. To date, the responses to an AVPA antagonist have only been examined in one study in patients with congestive heart failure (21). In that study, AVPA had no effect in patients with stable heart failure who received conventional antifailure therapy. These patients all had normal plasma levels of AVP and PRA and only mildly elevated NE. However, a marked vasodilator response was observed in a single patient with unstable severe heart failure and markedly elevated levels of AVP, PRA, and NE.

The potential role of vasopressin as a vasoconstrictor hormone in heart failure was examined in animals with adriamycin cardiomyopathic heart failure in three ways: by measurement of plasma vasopressin levels; by examining the hemodynamic response to vasopressin infusion; and by determining the response to blockade of the vascular effects of vasopressin using specific peptide antagonists. Plasma vasopressin levels were not significantly different in animals with heart failure compared with normal controls. However, increased sensitivity to vasopressin in animals with heart failure was suggested by the significant rise in peripheral vascular resistance in these animals, but not in controls, in response to infusion of $2.5 \mathrm{ng} / \mathrm{kg} \cdot \mathrm{min}$ vasopressin, although plasma levels were similar. The $25 \mathrm{ng} /$ $\mathrm{kg} \cdot \mathrm{min}$ infusion rate increased resistance in both normals and animals with heart failure, but the increase in the latter group was significantly greater than in the normals despite lower plasma vasopressin levels. This increased sensitivity to vasopressin in 
heart failure may be due to impaired baroreflex activity. Vasopressin has specific effects on baroreflex mechanisms that tend to buffer its pressor actions $(22,23)$, and vasopressin infusion causes a greater decrease in lumbar (24) and renal (25) sympathetic nerve activity than equipressor doses of phenylephrine. Vasopressin sensitivity is increased in baroreceptor denervated animals (26) and in patients with impaired baroreflexes due to autonomic neuropathy (27). The markedly attenuated baroreceptor reflex described in heart failure (28) may similarly increase sensitivity to vasopressin. Alternatively, vasopressin's influence on baroreceptor mechanisms may be altered in heart failure (22-25) so that it no longer inhibits sympathetic activity, leaving vasopressin's direct vasoconstrictor actions unopposed.

The results of vasopressin blockade with AVPA provide further evidence for a role for vasopressin as a vasoconstrictor in heart failure. The AVPA produced significant falls in blood pressure and peripheral resistance and an increase in cardiac output in rabbits with heart failure. In contrast, neither the administration of vehicle to animals with heart failure nor the administration of AVPA to normal controls resulted in any significant hemodynamic change. Since AVP levels were not elevated in animals with heart failure, the vasodilator response to AVPA observed in these animals may be explained by an increased sensitivity to AVP. A second possibility is that the AVPA acted centrally rather than peripherally. A nonselective vasodilatory response seems unlikely, as these analogues appear to be highly selective antagonists to the vascular effects of AVP $(8,10,19)$ and do not produce vasodilation in normal controls. An alternative possibility, recently raised, is that vasopressin might cause vasodilation by its action on antidiuretic receptors when its vasoconstrictor action is blocked (29).

After treatment with the vasopressin antagonist, plasma NE levels increased in animals with heart failure, suggesting that blockade resulted in activation of the sympathetic nervous system. A small but significant fall in PRA levels was observed in animals with heart failure after treatment with the AVPA. This is surprising, since vasopressin is known to suppress renal renin release, although the mechanisms have not been defined (30). Moreover, the fall in blood pressure and increased NE levels after AVPA would tend to increase PRA. A possible explanation for the fall in PRA after AVPA is that the antagonist may improve renal blood flow, which is markedly reduced in this model of heart failure (14). Another possibility is that the fall in PRA was a result of antidiuretic agonist activity of the vasopressin analogue. The changes in PRA levels after the AVPA may have contributed to its hemodynamic effects, although this is considered unlikely since the changes were quite small and would tend to be offset by the changes in NE.

In summary, this study provides evidence for a vasoconstrictor role for vasopressin in an animal model of low output congestive heart failure. Although resting plasma levels of AVP were not elevated, sensitivity to exogenous vasopressin was increased and blockade of the vascular effects of vasopressin produced significant falls in blood pressure and peripheral vascular resistance in animals with heart failure. In this model of heart failure, all three vasoconstrictor systems, namely the sympathetic, renin-angiotensin, and vasopressin, appear to be activated.

\section{Acknowledgments}

We are grateful to Dr. C. Arblaster of Farmitalia Carlo Erba for supplies of adriamycin. Miss L. Trigg provided expert technical assistance.
Leonard Arnolda was the recipient of a fellowship from the National Health and Medical Research Council of Australia, which also provided a Grant-in-Aid in support of the study.

\section{References}

1. Thomas, J. A., and B. H. Marks. 1978. Plasma norepinephrine in congestive heart failure. Am. J. Cardiol. 41:233-243.

2. Kluger, J., R. J. Cody, and J. H. Laragh. 1982. The contributions of sympathetic tone and the renin-angiotensin system to severe chronic congestive heart failure: response to specific inhibitors (prazosin and captopril). Am. J. Cardiol. 49:1667-1674.

3. Dzau, V. J., W. S. Colucci, N. K. Hollenberg, and G. H. Williams. 1981. Relation of the renin-angiotensin-aldosterone system to clinical state in congestive heart failure. Circulation. 63:645-651.

4. Szatalowicz, V. L., P. E. Arnold, C. Chaimowitz, D. Bichet, T. C. Berl, and R. W. Schrier. 1981. Radioimmunoassay of plasma arginine vasopressin in hyponatraemic patients with congestive heart failure. $N$. Engl. J. Med. 305:263-266.

5. Riegger, G. A. J., G. Liebau, and K. Kochsiek. 1982. Antidiuretic hormone in congestive heart failure. Am. J. Med. 72:49-52.

6. Zucker, I. H., L. Share, and J. P. Gilmore. 1979. Renal effects of left atrial distension in dogs with chronic congestive heart failure. $\mathbf{A m}$. J. Physiol. 236(4):H554-H560.

7. Riegger, A. J. G., and G. Liebau. 1982. The renin-angiotensinaldosterone system, antidiuretic hormone and sympathetic nerve activity in an experimental model of congestive heart failure in the dog. Clin. Sci. 62:465-469.

8. Manning, M., B. Lammek, M. Kruszynski, J. Seto, and W. H. Sawyer. 1982. Design of potent and selective antagonists of the vasopressor responses to arginine-vasopressin. J. Med. Chem. 25:408-414.

9. Schwartz, J., and I. A. Reid. 1981. Effect of vasopressin blockade on blood pressure regulation during haemorrhage in conscious dogs. Endocrinology. 109:1778-80.

10. Aisenbrey, G. A., W. A. Handelman, P. Arnold, M. Manning, and R. W. Schrier. 1981. Vascular effects of arginine vasopressin during fluid deprivation in the rat. J. Clin. Invest. 67:961-968.

11. Ishikawa, S. E., and R. W. Schrier. 1984. Vascular effects of arginine vasopressin, angiotensin II, and norepinephrine in adrenal insufficiency. Am. J. Physiol. 46:H104-H113.

12. Pullan, P. T., C. I. Johnston, W. P. Anderson, and P. I. Korner. 1980. Plasma vasopressin in blood pressure homeostasis and in experimental renal hypertension. Am. J. Physiol. 239:H81-87.

13. Jaenke, R. S., D. Deprez de Campaneere, and A. Trouet. 1980. Cardiotoxicity and comparative pharmacokinetics of six anthracyclines in the rabbit. Cancer Res. 40:3530-3536.

14. Arnolda, L., B. McGrath, M. Cocks, E. Sumithran, and C. Johnston. 1985. Adriamycin cardiomyopathy in the rabbit-an animal model of low output congestive heart failure with activation of vasoconstrictor mechanisms. Cardiovasc. Res. 19:378-382.

15. Korner, P. I., J. R. Oliver, and D. J. Casley. 1980. Effect of dietary salt on haemodynamics of established renal hypertension in the rabbit: implications for the autoregulatory theory of hypertension. $\mathrm{Hy}$ pertension. 2:794-801.

16. Woods, R. L., and C. I. Johnston. 1982. Role of vasopressin in hypertension: studies using the Brattleboro rat. Am. J. Physiol. 242:F727F732.

17. McGrath, B. P., S. P. Lim, L. Leversha, and A. Shanahan. 1981. Myocardial and peripheral catecholamine responses to acute coronary artery constriction before and after propranolol treatment in the anaesthetised dog. Cardiovasc. Res. 15:28-34.

18. Elliott, J. M., M. J. West, and J. Chalmers. 1985. Effects of vasopressin on heart rate in conscious rabbits. J. Cardiovasc. Pharmacol. 7:6-11.

19. Kruszynski, M., B. Lammek, and M. Manning. 1980. [1-( $\beta$-Mercapto- $\beta, \beta$-cyclopentamethylenepropionic acid),2-(o-methyl) tyrosine] arginine vasopressin and [1-( $\beta$-Mercapto- $\beta, \beta$-cyclopentamethylenepro- 
pionic acid)] arginine vasopressin, two highly potent antagonists of the vasopressor response to arginine-vasopressin. J. Med. Chem. 23:364368.

20. Riegger, G. A. J., G. Liebau, E. Bauer, and K. Kochsiek. 1985. Vasopressin and renin in high output heart failure of rats: hemodynamic effects of elevated plasma hormone levels. J. Cardiovasc. Pharmacol. 7:1-5.

21. Nicod, P., B. Waeber, J. Bussien, J. Goy, P. Turini, J. Nussberger, K. G. Hofbauer, and H. R. Brunner. 1985. Acute hemodynamic effect of a vascular antagonist of vasopressin in patients with congestive heart failure. Am. J. Cardiol. 55:1043-1047.

22. Cowley, A. W., D. Merrill, J. Osborn, and B. J. Barber. 1984. Influence of vasopressin and angiotensin on baroreflexes in the dog. Circ. Res. 54:163-172.

23. Johnston, C. I. 1985. Vasopressin in circulatory control and hypertension. J. Hypertension. 3:557-569.

24. Undesser, K. P., E. M. Hasser, J. R. Haywood, A. K. Johnson, and V. S. Bishop. 1985. Interactions of vasopressin with the Area Postrema in arterial baroreflex function in conscious rabbits. Circ. Res. 56: 410-417.
25. Guo, G. B., F. M. Sharabi, F. M. Abboud, and P. G. Schmid. 1982. Vasopressin augments baroreflex inhibition of lumbar sympathetic nerve activity in rabbits. Circulation. 66(Suppl. II):34. (Abstr.)

26. Cowley, A. W., E. Monos, and A. C. Guyton. 1974. Interaction of vasopressin and the baroreceptor reflex system in regulation of arterial blood pressure in the dog. Circ. Res. 34:505-514.

27. Mohring, J., K. Glanzer, J. A. Maciel, Jr., R. Düsing, H. F. Kramer, R. Arbogast, and J. Koch-Weser. 1980. Greatly enhanced pressor response to antidiuretic hormone in patients with impaired cardiovascular reflexes due to idiopathic orthostatic hypotension. J. Cardiovasc. Pharmacol. 2:367-376.

28. Ferguson, D. W., F. M. Abboud, and A. L. Mark. 1984. Selective impairment of baroreflex-mediated vasoconstrictor responses in patients with ventricular dysfunction. Circulation. 69:451-460.

29. Liard, J. F., and J. C. Spadone. 1984. Hemodynamic effects of antagonists of the vasoconstrictor action of vasopressin in conscious dogs. J. Cardiovasc. Pharmacol. 6:713-719.

30. Reid, I. A., J. Schwartz, L. Ben, J. Maselli, and L. C. Keil. 1983. Interactions between vasopressin and the renin-angiotensin system. Prog. Brain Res. 60:475-491. 